\title{
Effectiveness of Ear Splint Therapy for Ear Deformities
}

\author{
Ji Eun Woo, MD, Yul-Hyun Park, MD, Eun Ji Park, MD, Kyu Yong Park, PT, \\ Sun Hee Kim, PT, MS, Shin-Young Yim, MD, PhD
}

The Center for Torticollis, Department of Physical Medicine and Rehabilitation, Ajou University School of Medicine, Suwon, Korea

\begin{abstract}
Objective To present our experience with ear splint therapy for babies with ear deformities, and thereby demonstrate that this therapy is an effective and safe intervention without significant complications.

Methods This was a retrospective study of 54 babies ( 35 boys and 19 girls; 80 ears; age $\leq 3$ months) with ear deformities who had received ear splint therapy at the Center for Torticollis, Department of Physical Medicine and Rehabilitation, Ajou University Hospital between December 2014 and February 2016. Before the initiation of ear splint therapy, ear deformities were classified with reference to the standard terminology. We compared the severity of ear deformity before and after ear splint therapy by using the physician's ratings. We also compared the physician's ratings and the caregiver's ratings on completion of ear splint therapy.

Results Among these 54 babies, 41 children (58 ears, 72.5\%) completed the ear splint therapy. The mean age at initiation of therapy was $52.91 \pm 18.26$ days and the treatment duration was $44.27 \pm 32.06$ days. Satyr ear, forwardfacing ear lobe, Darwinian notch, overfolded ear, and cupped ear were the five most common ear deformities. At the completion of therapy, the final physician's ratings of ear deformities were significantly improved compared to the initial ratings $(8.28 \pm 1.44$ vs. $2.51 \pm 0.92 ; \mathrm{p}<0.001)$. There was no significant difference between the physician's ratings and the caregiver's ratings at the completion of ear splint therapy $(8.28 \pm 1.44 \mathrm{vs.} 8.0 \pm 1.61 ; \mathrm{p}=0.297)$.

Conclusion We demonstrated that ear splint therapy significantly improved ear deformities in babies, as measured by quantitative rating scales. Ear splint therapy is an effective and safe intervention for babies with ear deformities.
\end{abstract}

Keywords Ear auricle, External ear, Congenital abnormalities, Splints, Infant

Received May 26, 2016; Accepted July 26, 2016

Corresponding author: Shin-Young Yim

The Center for Torticollis, Department of Physical Medicine and Rehabilitation, Ajou University School of Medicine, 164 World cup-ro, Yeongtong-gu, Suwon 16499, Korea. Tel: +82-31-219-5284, Fax: +82-31-219-5209, E-mail: syyim@ajou.ac.kr

ORCID: Ji Eun Woo (http://orcid.org/0000-0002-3401-6890); Yul-Hyun Park (http://orcid.org/0000-0003-3103-293X); Eun Ji Park (http://orcid. org/0000-0002-4679-5553); Kyu Yong Park (http://orcid.org/0000-0002-3872-2872); Sun Hee Kim (http://orcid.org/0000-0002-5830-5910); Shin-Young Yim (http://orcid.org/0000-0002-8521-6331).

@ This is an open-access article distributed under the terms of the Creative Commons Attribution Non-Commercial License (http://creativecommons.org/ licenses/by-nc/4.0) which permits unrestricted noncommercial use, distribution, and reproduction in any medium, provided the original work is properly cited. Copyright $\odot 2017$ by Korean Academy of Rehabilitation Medicine 


\section{INTRODUCTION}

The external ear, also known as the auricle or pinna, consists of skin, cartilage, and seven intrinsic muscles [1]. Congenital ear anomalies are defined as malformations or deformations. Ear malformations are caused by embryologic maldevelopment. As early as in week 4 of gestation, the auricle, the auditory canal, and the middle ear are formed from an ectodermal protuberance of the first two branchial arches. The auricle develops from the hillocks of the second branchial arch with the formation of the lobule, the antihelix, and the dorsocaudal portion of the helix. In contrast, the cartilage of the tragus is formed from the first branchial arch. Therefore, in case of an incomplete fusion of the aggregations of the branchial arches, malformations of the external ear and the middle ear can develop during the embryonic stage between the fourth and ninth week of gestation [2]. Malformations are characterized by a partial absence of the skin or cartilage resulting in a constricted or underdeveloped pinna and generally require surgical correction. Ear deformities are characterized by a normal chondro-cutaneous component with an abnormally shaped pinna caused by deforming forces.

It has been reported that although $30 \%$ of newborn ear deformities will self-correct, approximately $13 \%$ of children at the age of 10 years still have an ear deformity $[3,4]$. Congenital muscular torticollis (CMT) is the one of the most common musculoskeletal conditions in the field of pediatric rehabilitation, and asymmetry of the ears is one of the characteristic features of CMT. A cupped ear on the CMT side and a flattened ear on the contralateral side are the common ear deformities in CMT [5]. Since we have been requested to present the management of ear deformities encountered in babies with CMT, it was realized that comprehensive management of concurrent conditions in CMT, such as ear deformity and plagiocephaly, is necessary along with management of CMT per se. Our clinical experience suggests that some babies with deformational plagiocephaly not related to CMT also had ear deformities. It seems to be associated with the preference for placing the head to one side, resulting in ear deformities. As our clinical experience has grown, we have realized that ear deformity is not an uncommon condition in the field of pediatric rehabilitation.

Children and adults with ear deformities experience more psychological distress, anxiety, self-consciousness, behavioral problems, and social avoidance than those with normally shaped ears. Ear deformities can usually be corrected by appropriate splinting in the neonatal period. Since the first publication from Japan in the 1980s [6], it has been demonstrated that permanent correction can be achieved by forcing the ear into the desired position for several weeks by using an ear splint [7-9].

An ear splint is a mechanical device that has been used to hold the pinna in position for nonsurgical correction of different ear deformities. Different soft, elastic, and moldable materials in combination with surgical tape have been used as ear splints over a period of weeks to months [10]. In 2010, ear splint was approved by US Food and Drug Administration as a class I medical device. Other examples of class I devices include elastic bandages, examination gloves, and hand-held surgical instruments [11]. In Korea, a few different commercial ear splints are available.

While ear splint therapy has been used to correct ear deformities in the newborn, thus avoiding surgery with its possible complications [12], it has not achieved widespread usage, mainly due to lack of recognition by health professionals and the general population. Few studies have reported about ear splint therapy in Korea $[13,14]$. This article presents our experience with ear splint therapy for babies with ear deformities, from the perspective of pediatric rehabilitation physicians.

\section{MATERIALS AND METHODS}

This was a retrospective study conducted at a single tertiary medical center. This research was approved by the Institutional Review Board.

\section{Subjects}

Babies were screened from those who visited the Department of Physical Medicine and Rehabilitation from December 2014 to February 2016 for ear deformities that were identified by caregivers. The inclusion criteria were babies with ear deformities aged 3 months or younger. Exclusion criteria were as follows: (1) babies older than 3 months at the time of initiation of ear splinting; (2) skin problems around the ear that need to be treated; (3) ear malformations characterized by a partial absence of the skin or cartilage resulting in a constricted or underde- 
Table 1. Characteristics of the subjects $(n=54)$

\begin{tabular}{|c|c|}
\hline Characteristic & Value \\
\hline $\begin{array}{l}\text { Age at the initiation of ear } \\
\text { splint therapy (day) }\end{array}$ & $52.91 \pm 18.26(21-90)$ \\
\hline$\leq 1$ month & $39(72.22)$ \\
\hline$>1$ and $\leq 2$ months & $14(25.93)$ \\
\hline$>2$ and $\leq 3$ months & $1(1.85)$ \\
\hline Treatment duration $^{\text {a) }}$ (day) & $44.27 \pm 32.06(8-169)$ \\
\hline Follow-up period $^{\text {a) }}$ (day) & $66.85 \pm 49.53(12-193)$ \\
\hline Sex (boy:girl) & $35: 19$ \\
\hline Ears for ear splint therapy & 80 \\
\hline Diagnosed with CMT & $37(68.52)$ \\
\hline Gestational age (wk) & $39.15 \pm 1.38$ \\
\hline Preterm birth & $2(3.70)$ \\
\hline Birth weight (g) & $3,218 \pm 377$ \\
\hline$<2,500 \mathrm{~g}$ & $1(1.85)$ \\
\hline \multicolumn{2}{|l|}{ Type of delivery } \\
\hline Spontaneous vaginal delivery & $35(64.81)$ \\
\hline Elective caesarean section & $15(27.78)$ \\
\hline Emergency caesarean section & $4(7.41)$ \\
\hline \multicolumn{2}{|c|}{$\begin{array}{l}\text { Values are presented as mean } \pm \text { standard deviation (range) } \\
\text { or number }(\%) \text {. } \\
\text { CMT, congenital muscular torticollis. } \\
\text { a) Treatment duration and follow-up period were evalu- } \\
\text { ated in } 41 \text { babies who completed the ear splint therapy. }\end{array}$} \\
\hline
\end{tabular}

veloped pinna and requiring surgical correction [7]; (4) a history of allergic reaction to an adhesive tape. The demographic characteristics shown in Table 1 were collected by reviewing the medical records. Subjects with CMT were identified. CMT was diagnosed when the following two conditions were met: (1) significant tightness or thickening of the unilateral sternocleidomastoid muscle with ipsilateral head tilting and/or rotation of the chin toward the contralateral side; (2) thickness of the sternocleidomastoid muscle of the involved side more than $2 \mathrm{~mm}$ greater than that of the sternocleidomastoid muscle of the contralateral side, along with increased echogenicity on ultrasonography.

\section{Classification and assessment of severity of the ear deformity before the initiation of splint therapy}

Before the initiation of splint therapy, ear deformities were classified with reference to the standard terminology provided in a previous article [1]. Discrepancies were resolved by discussion between authors. The severity of ear deformity was also evaluated by a physician using a visual analog scale from 0 to 10 , where 0 denoted the worst ear deformity and 10 denoted a normally shaped ear. We evaluated the severity of ear deformity by using a visual analogue scale (VAS) with numerical rating scales from 0 to 10. VAS is an instrument that tries to measure a characteristic that is believed to range across a continuum of values and cannot easily be directly measured. It is often used in clinical research to measure the intensity or frequency of various symptoms $[15,16]$. We thought that the severity of ear deformity ranges across a continuum from none to an extreme amount of deformity. This spectrum appears continuous and does not take discrete jumps. Therefore, we used VAS rather than Likert scale which categorizes the parameter into none, mild, moderate, and severe. The simplest VAS is a straight horizontal line of fixed length, usually $100 \mathrm{~mm}$. The ends are defined as the extreme limits of the ear deformity [17] orientated from the left (worst) to the right (best). The severity of ear deformity was also categorized into severe (0-2), moderate (3-5), minimal (6-8), and normal (9-10).

\section{Ear splint therapy}

Ear splint therapy was performed as an outpatient procedure by the corresponding author. No anesthesia was needed. A commercially available ear splint (Babyears; Linktechkorea Co. Ltd., Seoul, Korea) was used in combination with a tape. The splint was made with a medicalgrade stainless wire core segment embedded in a silicone tube, with caps of the following six different lengths: 40 , $45,50,55,60$, and $65 \mathrm{~mm}$ for each end.

Therapy was conducted as follows:

(1) The skin of the ear was cleaned with alcohol swabs and dried.

(2) A no-sting barrier film (Cavilon; 3M Health Care, St. Paul, MN, USA) was applied by a spray 2 minutes before each round of ear splint therapy to prevent medical adhesive-related skin injury.

(3) An appropriately sized ear splint was selected.

(4) If it was deemed necessary to secure the adhesive tape to the scalp, the hair around the ear was shaved using a hair clipper for children.

(5) The babies were held in their caregivers' arms in a lateral decubitus position with the ear to be treated facing up.

(6) The splint was placed in the scaphal hollow to de- 
fine the anti-helical fold and to serve as a supporting pillar.

(7) The splint was then secured with Steri-Strips (3M Health Care) and sterile Micropore tape (3M Health care). The ear was taped to the temporal scalp in cases in which the ear protruded.

(8) Caregivers were asked to leave the splint in place 24 hours a day and to return with their babies at weekly intervals. The splint was removed by the caregivers before each clinical follow-up. The ears were not allowed to get wet. If the tape came loose, it was changed or more tape was applied.

(9) At every visit, correction of ear deformities was checked. The splint was adjusted following the same procedure mentioned above, if satisfactory correction was not achieved. The splint was removed when correction of deformities was satisfactory for both the physician and the caregivers.

(10) Based on the previous study $[7,9,18]$, the termination of the splint therapy was determined when the corrected ear shape was stable after achieving satisfactory correction, which took at least one more week.

(11) Photographs were taken at every visit before applying splint therapy.

\section{Analysis of effectiveness of ear splint therapy}

At the completion of the therapy, the severity of ear deformity was again evaluated by both the physician and caregiver, using the same visual analog scale utilized above. We compared the physician's rating and the caregiver's rating of the severity of each deformity at the completion of the therapy.

The initial and final physician's ratings were also compared according to the classification of ear deformities, in order to determine whether there were differences in the effectiveness of therapy according to the type of ear deformity. Side effects and complications during ear splint therapy were investigated.

\section{Statistical analysis}

The results are expressed as mean \pm standard deviation. For statistics, we used the Statistical Package for the Social Sciences ver. 15 (SPSS Inc., Chicago, IL, USA). Paired t-test was used for comparing the initial and final physician's ratings for the severity of ear deformity. The ttest was used for comparison of the final physician's ratings and the final caregiver's rating for the severity of ear deformity. ANOVA test was used for the initial and final physician's ratings according to the type of ear deformity. A $p<0.05$ was considered statistically significant.

\section{RESULTS}

\section{Ear splint therapy}

Among 62 babies with ear deformities who visited our clinic between December 2014 and January 2016, 54 babies (a total of 80 ears) were enrolled in this study. Among these 54 babies, 41 (a total of 58 ears, $72.5 \%$ ) completed the ear splint therapy. The flowchart of subjects' enrollment is presented in Fig. 1. The characteristics of the subjects $(\mathrm{n}=54)$ are presented in Table 1. Among these 54 subjects, 37 (68.52\%) had ear deformities concurrent with CMT.

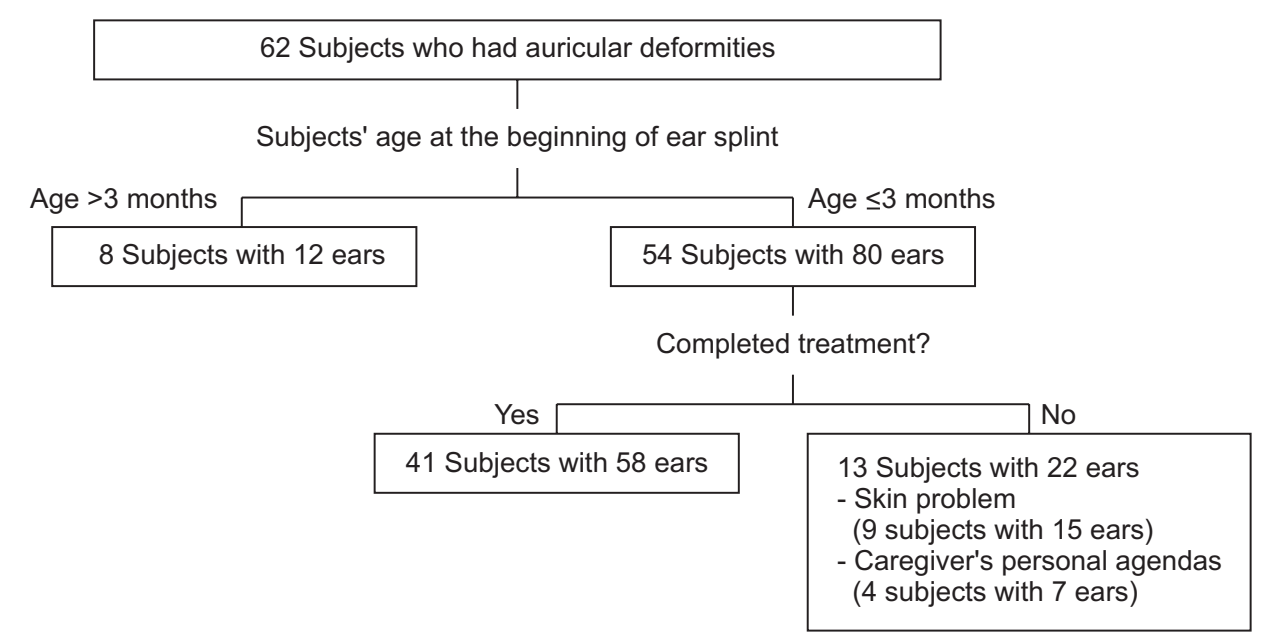

Fig. 1. Flowchart of subject enrollment. 
Table 2. Distribution of the subjects according to the type of ear deformity and the initial physician's rating scale (n=54, 80 ears)

\begin{tabular}{|c|c|c|c|c|c|c|}
\hline Type & Definition & Figure & $\begin{array}{l}\text { No. of } \\
\text { ears }\end{array}$ & IPR & FPR & FCR \\
\hline Helix & $\begin{array}{l}\text { The outer rim of the ear that extends from the } \\
\text { superior insertion of the ear on the scalp (root) } \\
\text { to the termination of the cartilage at the earlobe }\end{array}$ & & & & & \\
\hline Satyr & $\begin{array}{l}\text { Sharp pointed superior portion of the ear, with } \\
\text { variable overfolding of the helix }\end{array}$ & & 28 & 2.24 & 8.70 & 7.67 \\
\hline Darwinian notch & $\begin{array}{l}\text { Small defect of the helical fold that lies at the } \\
\text { junction of the superior and descending } \\
\text { portions of the helix }\end{array}$ & & 14 & 3.29 & 8.14 & 8.33 \\
\hline Overfolded & $\begin{array}{l}\text { Excessive curling of the helix edge, whereby the } \\
\text { free edge is parallel to the plane of the ear }\end{array}$ & & 11 & 2.57 & 8.00 & 7.80 \\
\hline Cryptotia & $\begin{array}{l}\text { Invagination of the superior part of the auricle } \\
\text { under a fold of temporal skin }\end{array}$ & & 4 & 2.00 & 10.00 & 8.33 \\
\hline Lop & $\begin{array}{l}\text { Excessive curling of the helix edge, where the } \\
\text { usual convexity of the posterior border of the } \\
\text { ear is lost }\end{array}$ & & 2 & 0.50 & 8.00 & 9.00 \\
\hline Crimped & $\begin{array}{l}\text { Linear, circumferential indentation in the } \\
\text { convexity of the outer surface of the helix }\end{array}$ & & 2 & 2.00 & 5.00 & 8.00 \\
\hline Antihelix & $\begin{array}{l}\text { A Y-shaped curved cartilaginous ridge arising } \\
\text { from the antitragus and separating the concha, } \\
\text { triangular fossa, and scapha }\end{array}$ & & & & & \\
\hline Cupped & $\begin{array}{l}\text { Laterally protruding ear that lacks antihelical } \\
\text { folding including absence of inferior and } \\
\text { superior crura }\end{array}$ & & 9 & 2.14 & 8.14 & 7.80 \\
\hline Stahl & $\begin{array}{l}\text { Third crus arising at or above the normal } \\
\text { bifurcation of the antihelix }\end{array}$ & & 2 & 1.50 & 9.50 & 6.50 \\
\hline Lobe & The soft, fleshy, inferior part of the pinna & & & & & \\
\hline Forward facing & $\begin{array}{l}\text { Positioning of the anterior surface of the ear lobe } \\
\text { in a more coronal plane than the remainder of } \\
\text { the ear }\end{array}$ & & 23 & 3.00 & 8.50 & 9.25 \\
\hline \multicolumn{7}{|l|}{ Other parts } \\
\hline Protruding & $\begin{array}{l}\text { Outer edge of the helix more than } 2 \mathrm{~cm} \text { from the } \\
\text { mastoid at the point of maximum distance }\end{array}$ & & 2 & 3.50 & 7.50 & 7.50 \\
\hline
\end{tabular}

IPR, initial physician's rating (from 0 to 10, 11 scale); FPR, final physician's rating; FCR, final caregiver's rating each ear had 1.21 types of ear deformities on average. 
The mean age at the initiation of therapy was 52.91 \pm 18.26 days (range, 21-90 days), the follow-up period was $66.85 \pm 49.53$ days (range, $12-193$ days), and the treatment duration was $44.27 \pm 32.06$ days (range, 8-169 days). Thirteen subjects (22 ears, $27.5 \%$ ) could not complete the therapy due to skin problems (15 ears of 9 babies) and caregiver's personal agendas (7 ears of 4 babies) (Fig. 1).

\section{Classification and assessment of the severity of ear deformity before initiation of ear splint therapy}

The distribution of ears according to the type of ear deformity is presented in Table 2 . The mean initial physician's rating was $2.51 \pm 0.92$. A total of 80 ears of 54 babies had 97 ear deformities, which indicates that, on average, each ear had 1.21 types of ear deformities. Satyr ear (28 ears, 35\%), forward-facing ear lobe (23 ears, 28.75\%), Darwinian notch (14 ears, 17.5\%), overfolded ear (11 ears, $13.75 \%$ ), and cupped ear (9 ears, $11.25 \%$ ) were the five most common ear deformities.

\section{Analysis of effectiveness of ear splint therapy}

Fig. 2 shows photographs at pre-treatment (left in each row), treatment (middle in each row) and post-treatment (right in each row) for Stahl's ear (Fig. 2A), Satyr ear (Fig. 2B), and lop ear (Fig. 2C), which show improvement post-treatment. Fig. 3A shows that although the initial physician's ratings of the severity of ear deformities were severe $(n=21,51.22 \%)$ to moderate $(n=20,48.78 \%)$, the final physician's ratings were significantly improved to moderate $(n=3,7.32 \%)$, minimal $(n=20,48.78 \%)$, and
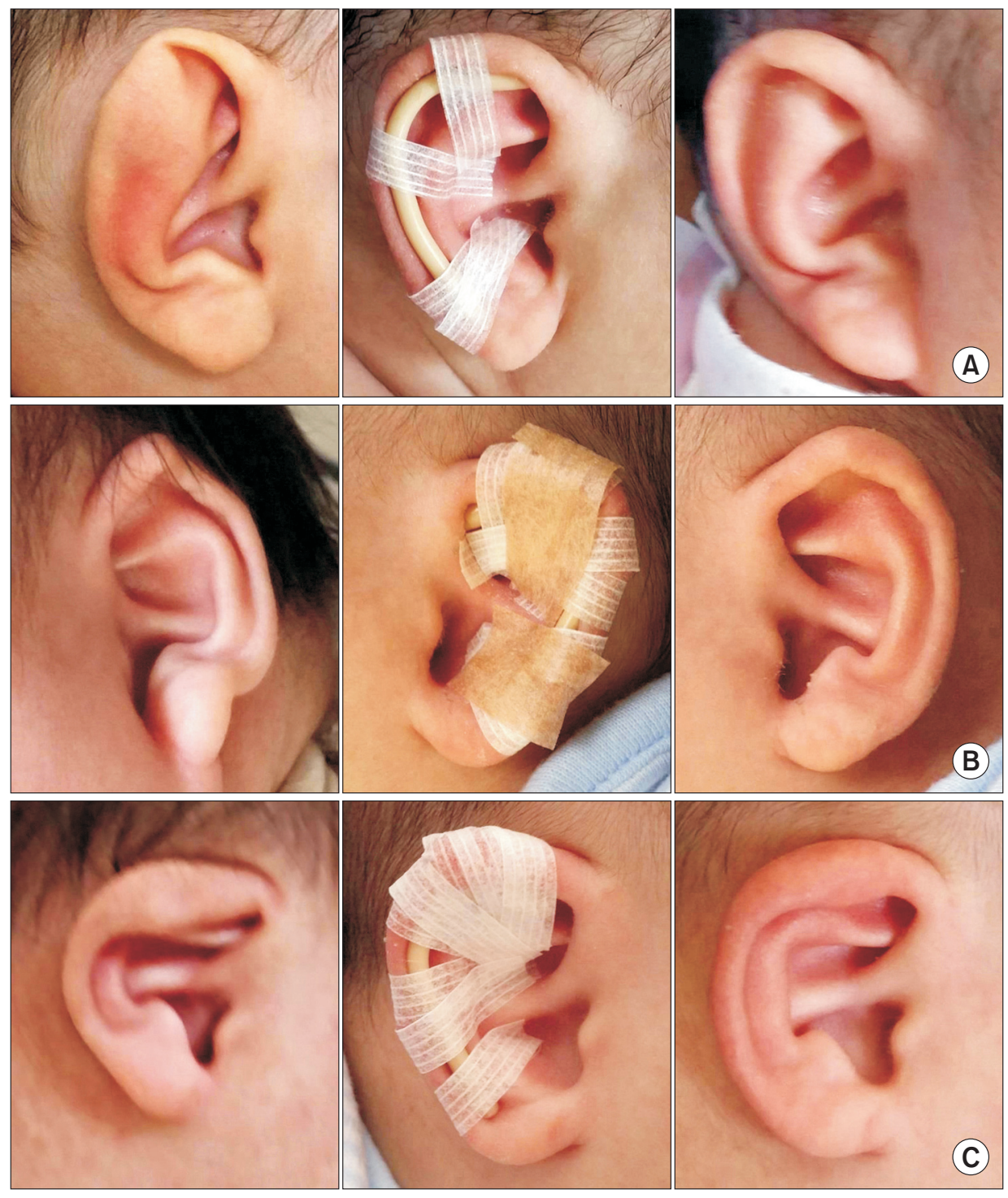
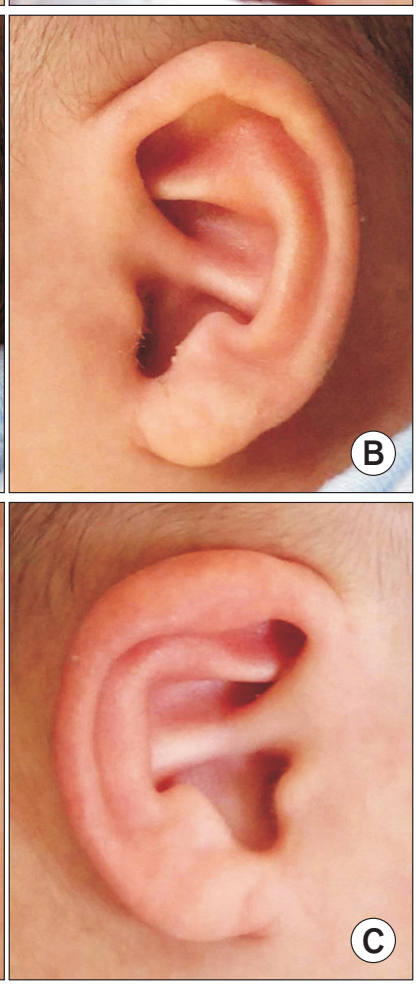

Fig. 2. Example of ear splint therapy. (A) A 2-month-old girl with right Stahl's ear. (B, C) A 1-monthold boy with left Satyr and right lop ear. Before treatment (left in each row), attached splint (center in each row), and after treatment (right in each row). 


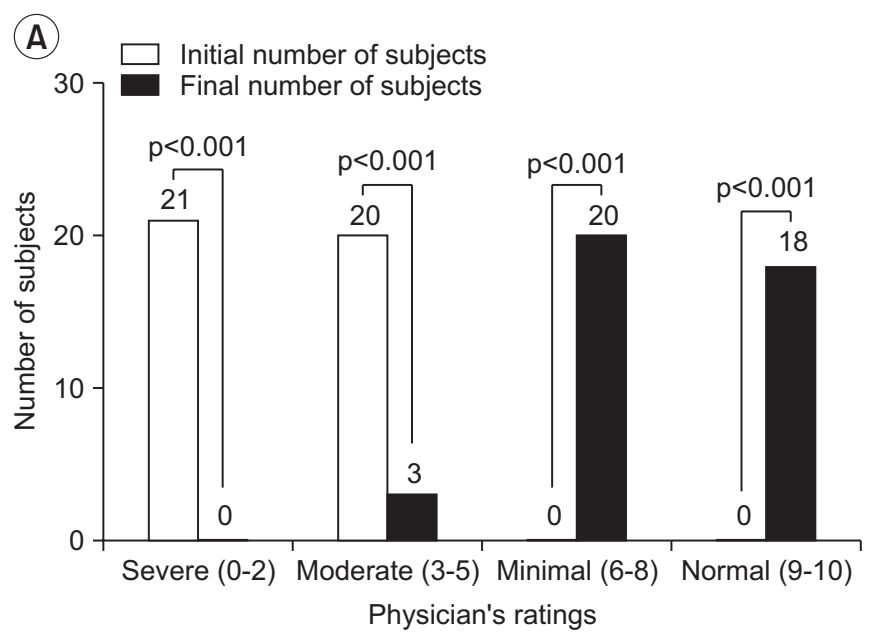

(B)

(C)

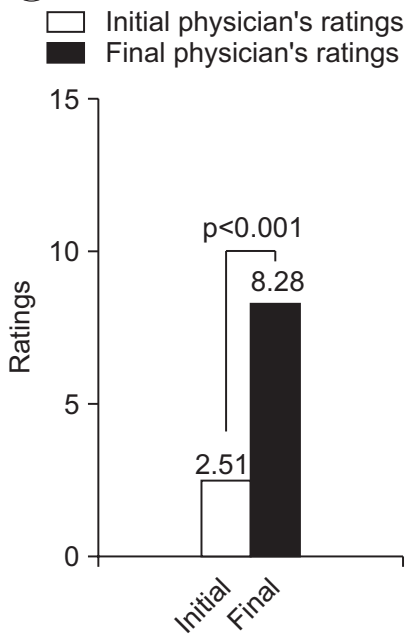

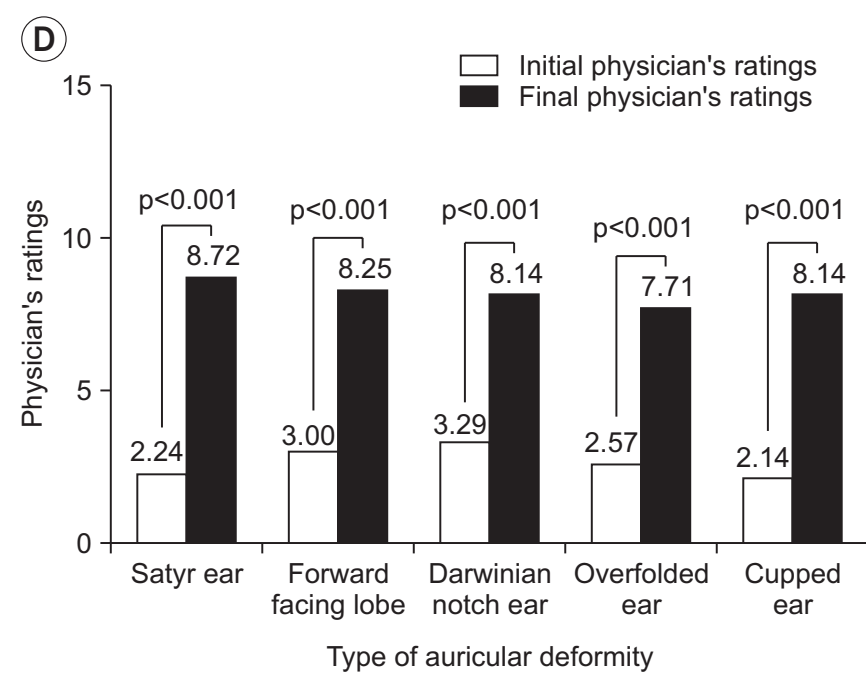

Fig. 3. Continued.

in the physician's ratings at the completion of therapy compared to the initial physician's ratings ( $8.28 \pm 1.44$ vs. $2.51 \pm 0.92 ; \mathrm{p}<0.001)$.

Although the caregivers and the physicians rated the severity of ear deformities as $8.0 \pm 1.61$ and $8.28 \pm 1.44$, respectively, there was no significant difference $(\mathrm{p}=0.297)$ between the physician's ratings and the caregiver's ratings at the completion of therapy (Fig. 3C).

The mean initial and final physician's ratings are shown in Table 2 according to the classification of the ear deformities. Regardless of the type of ear deformities, the comparison of the mean initial and final physician's ratings showed improvement in the deformities. The initial and final physician's ratings for the five most common ear deformities are also presented in Fig. 3D. Although all five ear deformities showed significant improvement with ear splint therapy $(p<0.001)$, there were no significant differences in improvement among the five deformities $(\mathrm{p}=0.22)$.

\section{Complications of ear splint therapy}

Twenty-nine (53.7\%) babies developed dermatologic problems, and 9 of these 29 babies could not complete the ear splint therapy. Among the 41 babies who completed the treatment schedule, 6 babies (14.63\%) showed repetitive scratching of the splinted ears and 20 babies (48.78\%) had minimal skin irritation or erosion. There were no severe complications such as necrosis of the skin or cartilage. normal $(\mathrm{n}=18,43.90 \%$; $\mathrm{p}<0.001)$. We compared the initial and final physician's ratings of severity of ear deformities (Fig. 3B), and we found significant improvement 


\section{DISCUSSION}

This study presents our experience with ear splint therapy for babies with ear deformities, and it demonstrates that ear splint therapy is an effective and safe intervention without significant complications. Sixty-eight percent of the subjects had ear deformities associated with CMT. Ear deformity is not a rare condition in the field of pediatric rehabilitation. Unfortunately, ear split therapy is relatively unknown to rehabilitation physicians. As a result, children are seldom treated at the age when splints can be applied. It is hoped that this article will provide an impetus for health professionals, especially for rehabilitation physicians to recognize non-surgical management of ear deformity.

A systematic review of ear split therapy showed that, with several types of therapy, the ear can be permanently kept in the desired shape without distortion. It was concluded that ear splinting is an elegant technique that should be practised on a wider scale than is done today [19]. A study on costs involved in ear screening and splinting versus daycare pinnaplasty revealed that ear splinting and daycare pinnaplasty cost $£ 77$ and $£ 560$, respectively [20]. In Korea, the cost of ear splint therapy is approximately one-tenth of the cost of pinnaplasty. Therefore, ear splint therapy is a cost-effective intervention for babies with ear deformities.

However, there are many unanswered questions regarding the usage of ear splints. Ear splint therapy provides the best results when it is performed by physicians who have substantial and professional knowledge of the normal anatomy of the external ear. However, since ear splints are commercially available without prescription in several countries through the Internet, the extent of involvement of less-qualified caregivers in ear splint therapy needs to be investigated. Because the first 6 weeks of the postnatal period might be complicated by medical issues, ear deformity might not be considered a priority. Although up to 6 weeks of age is considered the optimal time for ear splint therapy due to the pliability of the auricular cartilage, which is related to the estrogen level in babies, the maximum age at which splinting therapy should reasonably be offered is disputable. In addition, a comparison of effectiveness of specific types of ear splints needs to be performed.

The five most common ear deformities in the current study were Satyr ear (28 ears, 35\%), forward-facing ear lobe (23 ears, $28.75 \%$ ), Darwinian notch (14 ears, 17.5\%), overfolded ear (11 ears, 13.75\%), and cupped ear (9 ears, $11.25 \%)$. These findings differ from those of other studies, with cryptotia being the most frequently observed deformity among 275 ears in a study performed in Japan [21], and helical rim and Stahl deformities being the most common ear deformities among 158 ears in a study performed in New York [22]. This difference may be due to the small number of subjects in the current study. However, the frequency of ear deformities is not the subject of this study and it may be studied by other researchers in future studies. It is also unclear whether all deformed ears should be splinted. As reported, many ear deformities resolve spontaneously during the first few months after birth.

The anatomical appearance of ears varies depending on the race [23]; however, only a few studies about nonsurgical correction of congenital ear deformities have been published in Korea [13,14]. Therefore, we think that further studies are needed on the description and treatment of ear deformities in the Korean population.

The strength of this study is that we defined and illustrated the terms describing the major deformities of the ear based on the previous papers defining the morphology of regions of the human body [1]. Although there are substantial variations in the classification of ear deformities, this made us less dependent on individual opinion, thereby minimizing the misclassification of ear deformities.

This study has a number of limitations and the overall results must be interpreted with a degree of caution. First, the outcome assessment was done using subjective measurements. To date, there is no objective tool for the assessment of ear deformities, and most previous studies used subjective measurements $[7,18,24]$. To overcome this limitation, we assessed both the physician's and caregiver's rating scales and compared both measurements which showed no statistically significant difference. Future studies are needed to validate the objective measurement tool of ear deformities, such as length, width, position, and angulation of each ear deformity. Second, this article presented our experience with ear splint therapy for a small number of babies with ear deformities. Case selection could be biased by several factors, including whether the subjects' families and guard- 
ians could afford the time and the cost of the therapy, and whether they felt such a therapy would be worthwhile. Third, this study did not have a control group. It could be argued that if $30 \%$ of patients with ear deformities will self-correct, these children were unnecessarily treated. Unfortunately, there is currently no scientific method to predict which deformities will and will not improve. Fourth, case selection could be biased by several factors. The current study showed that $68 \%$ of the subjects had CMT. This study was conducted at a specialized medical facility where subjects are referred for management of CMT from all areas in Korea. In addition, there are only a few facilities for ear splint therapy in Korea. Therefore, more subjects with CMT along with ear deformities could be enrolled in this study.

Despite the limitations of this study, we demonstrated that ear splint therapy significantly improved ear deformities in babies. In conclusion, ear splint therapy is an effective and safe intervention for babies with ear deformities. Further studies in a large population are required in the near future.

\section{CONFLICT OF INTEREST}

No potential conflict of interest relevant to this article was reported.

\section{REFERENCES}

1. Hunter A, Frias JL, Gillessen-Kaesbach G, Hughes H, Jones KL, Wilson L. Elements of morphology: standard terminology for the ear. Am J Med Genet A 2009; 149A:40-60.

2. Bartel-Friedrich S, Wulke C. Classification and diagnosis of ear malformations. GMS Curr Top Otorhinolaryngol Head Neck Surg 2007;6:Doc05.

3. Smith W, Toye J, Reid A, Smith R. Nonsurgical correction of congenital ear abnormalities in the newborn: case series. Paediatr Child Health 2005;10:327-31.

4. Matsuo K, Hayashi R, Kiyono M, Hirose T, Netsu Y. Nonsurgical correction of congenital auricular deformities. Clin Plast Surg 1990;17:383-95.

5. Kuo AA, Tritasavit S, Graham JM Jr. Congenital muscular torticollis and positional plagiocephaly. Pediatr Rev 2014;35:79-87; quiz 87.

6. Kurozumi N, Ono S, Ishida H. Non-surgical correction of a congenital lop ear deformity by splinting with Reston foam. Br J Plast Surg 1982;35:181-2.

7. Leonardi A, Bianca C, Basile E, Ungari C, Arangio P, Filiaci F, et al. Neonatal molding in deformational auricular anomalies. Eur Rev Med Pharmacol Sci 2012; 16:1554-8.

8. Byrd HS, Langevin CJ, Ghidoni LA. Ear molding in newborn infants with auricular deformities. Plast Reconstr Surg 2010;126:1191-200.

9. Schonauer F, La Rusca I, Molea G. Non-surgical correction of deformational auricular anomalies. J Plast Reconstr Aesthet Surg 2009;62:876-83.

10. Sorribes MM, Tos M. Nonsurgical treatment of prominent ears with the Auri method. Arch Otolaryngol Head Neck Surg 2002;128:1369-76.

11. US Food and Drug Administration. EarWell ear correction splint [Internet]. Silver Spring: US Food and Drug Administration; c2017 [cited 2017 Jan 7]. Available from: http://www.accessdata.fda.gov/scripts/cdrh/ cfdocs/cfrl/ldetails.cfm?lid=263752.

12. van Wijk MP, Breugem CC, Kon M. A prospective study on non-surgical correction of protruding ears: the importance of early treatment. J Plast Reconstr Aesthet Surg 2012;65:54-60.

13. Park C. Correction of cryptotia using an external stretching device. Ann Plast Surg 2002;48:534-8.

14. Park JH, Kim KM, Lee YS, Kim YS, Kim YO. Nonoperative correction of congenital auricular deformities using a silicone splint. J Korean Soc Plast Reconstr Surg 2000;27:532-8.

15. Paul-Dauphin A, Guillemin F, Virion JM, Briancon S. Bias and precision in visual analogue scales: a randomized controlled trial. Am J Epidemiol 1999;150: 1117-27.

16. McCormack HM, Horne DJ, Sheather S. Clinical applications of visual analogue scales: a critical review. Psychol Med 1988;18:1007-19.

17. Streiner DL, Norman GR. Health measurement scales: a practical guide to their development and use. 4th ed. New York; Oxford University Press; 2008.

18. Tan S, Wright A, Hemphill A, Ashton K, Evans J. Correction of deformational auricular anomalies by moulding: results of a fast-track service. N Z Med J 2003;116:U584.

19. van Wijk MP, Breugem CC, Kon M. Non-surgical correction of congenital deformities of the auricle: a systematic review of the literature. J Plast Reconstr Aes- 
thet Surg 2009;62:727-36.

20. Fraser L, Starritt N, Melia L, Kubba H. Development of a screening service for neonatal ear deformity using neonatal hearing screeners and an information leaflet. Int J Pediatr Otorhinolaryngol 2013;77:538-43.

21. Yotsuyanagi T. Nonsurgical correction of congenital auricular deformities in children older than early neonates. Plast Reconstr Surg 2004;114:190-1.

22. Doft MA, Goodkind AB, Diamond S, DiPace JI, Kacker A, LaBruna AN. The newborn butterfly project: a shortened treatment protocol for ear molding. Plast Reconstr Surg 2015;135:577e-583e.

23. Swift B, Rutty GN. The human ear: its role in forensic practice. J Forensic Sci 2003;48:153-60.

24. Petersson RS, Recker CA, Martin JR, Driscoll CL, Friedman O. Identification of congenital auricular deformities during newborn hearing screening allows for nonsurgical correction: a Mayo Clinic pilot study. Int J Pediatr Otorhinolaryngol 2012;76:1406-12. 